\title{
Editorial
}

\section{Development and progress in branding research}

\author{
Journal of Brand Management (2008) 16, 117-118. doi:10.1057/bm.2008.40
}

Branding research has gained significant momentum in recent years. There are many more researchers from various business schools around the world who are investigating and writing about new and unchartered topics in branding. This clearly reflects on the growth, the confidence and maturity of the topic that played a significant role in ensuring further expansion of this field of study. The Journal of Brand Management has played a noteworthy role in disseminating current thinking and research to those interested in the topic. We are receiving and reviewing more papers both from the established marketing scholars and from the new and budding generation of brand researchers. This has created a great deal of excitement and a proliferation of interesting and new research agendas that have not been explored before. One of the strengths of the Journal of Brand Management is that it publishes papers that are scientifically rigorous and also communicate the value of the research to practicing managers.

As part of strategic growth of the journal, we have added yet more prestigious members on to our Editorial Board. We have also increased the number of world-class ad hoc reviewers for examining the quality of the papers being submitted. This has consistently improved the quality of the review process and has lead to an even higher quality of papers being published by the journal. A note of achievement is that we have seen an increase in the number of subscriptions; thus, we are confident that the papers we publish are read by many academics and practitioners around the world. Given this background, we are hosting several special issues addressing the myriad of new topics from the highly energetic and enthusiastic contributors, researchers and practitioners across boundaries.

The topics of the papers published in this issue range from brand image to design attributes. In the first paper, daSilva and Syed Alwi present a study in which practitioners are advised to link issues of corporate brand image, satisfaction and loyalty in the online context. The authors reported that informality dimension that was indicated as a weak factor by previous research is a strong dimension in this research setting. They also found that customer satisfaction, consumer behaviour intention/ loyalty intention have a direct relationship with corporate brand image. Using focus group, in-depth interviews and email survey, Vrontis and Paliwoda found that the wine industry in Cyprus is growing but still fragmented. They recommend that brand building is an effective means of creating differentiation by promoting Cyprus as a wine producing country and emphasising the wine-related history, heritage and culture of Cyprus. In the third paper, Moroko and Uncles introduce a typology of characteristics of successful employer brands. From a series of qualitative interviews with expert industry panel, the researchers found that employee branding has a distinct context for organisational research and theory development. The theory aligns HR and marketing functions of the organisation and reveals that the employment experience is conceptualised as a product by employees. Walvis, the author of the fourth paper, 
investigated the neuroscientific foundations for effective brand building. He questioned whether or not neuroscience can help identify regularities in the way branding can influence the outcome of memory-based choice situations. He posits that it is crucial to study how efficiently brands are evocated by customers' primary choice cues instead of focusing exclusively on brand evaluation. He also emphasises that marketers often fail to understand or nurture the deeper meaning of brands. The author reflects on the short-termism nature of the brand building strategy, and the paper emphasises that brand strength is diluted which then results in a wavering leadership. The fifth and last paper by $\mathrm{Na}$, Holland, Schakleton, Hwang and Melewar investigated the influence of design attributes on the importance of brand information in the product evaluation process by consumers. After stating the hypotheses, they selected 135 undergraduate students and randomly assigned the three types of conditions in testing the hypotheses. They found that using design attribute information to promote a product can shift the locus of equity. The paper recommends that companies should be able to differentiate their brands from competing brands by delineating specific criteria for design attribute information. This finding provides a clear understanding about how consumers evaluate brand attributes that leads to stability in consumer brand choice.

I hope you will enjoy reading the highly stimulating papers that we have published in this issue of the journal.

Thank you for your continuing support.

Happy reading!!

T. C. Melewar Joint Editor-in-Chief 